\title{
Complications of upper urinary system laparoscopic surgery: a single center experience with 942 cases
}

\author{
Mithat Ekşii ${ }^{1}$, Selçuk Şahin ${ }^{2} \oplus$, Nevzat Can Şener ${ }^{3} \oplus$, Kamil Gökhan Şeker ${ }^{4} \oplus$, İsmail Evren² ${ }^{\circledR}$, Serdar \\ Karadağ $^{2} \oplus$, Abdullah Hızır Yavuzsan ${ }^{5} \oplus$, Deniz Noyan Özlï${ }^{2}$, Volkan Tuğcu ${ }^{6} \odot$
}

${ }^{1}$ Department of Urology, Arnavutköy State Hospital, Istanbul, Turkey

${ }^{2}$ Department of Urology, Bakırköy Dr. Sadi Konuk Training and Research Hospital, Istanbul, Turkey

${ }^{3}$ Department of Urology, Adana City Training and Research Hospital, Adana, Turkey

${ }^{4}$ Department of Urology, Muş State Hospital, Muş, Turkey

${ }^{5}$ Department of Urology, Şişli Hamidiye Etfal Training and Research Hospital, İstanbul, Turkey

${ }^{6}$ Department of Urology, Memorial Bahçelievler Hospital, İstanbul, Turkey

\section{ABSTRACT}

Objectives: Since the introduction of laparoscopic nephrectomies, laparoscopic surgeries in the field of urology have become increasingly popular. Laparoscopic surgery has its advantages but carries the risk of complications like all interventions. In our study, we aimed to discuss our complication rates according to difficulty level by presenting our experiences with urological laparoscopic procedures for the upper urinary system.

Methods: This retrospective study includes 942 laparoscopic urological procedures performed by a single surgeon. The procedures divided into three groups according to the European Scoring System (ESS) Classification. The complication rate of each group was calculated separately.

Results: A total of 127 (13.4\%) complications were observed. Partial nephrectomy, nephroureterectomy and ureterolithotomy had the highest complication rates. Renal cyst excision, simple nephrectomy and radical nephrectomy had the lowest complication rates. According to the Clavien Complication Classification, the distributions of Grade 1, 2 and 3 complications were 29.1\% $(n=37), 57.4 \%(n=73)$ and $13.3 \%(n=17)$; respectively. The open conversion rate was $0.84 \%$. When procedures were classified as "easy", "difficult" and "very difficult" according to the ESS classification; complication rates were found $7.3 \%$ in the easy group, $13.3 \%$ in the difficult group and $16.6 \%$ in the very difficult group. There was no significant difference between the three groups in terms of complication rates $(p=0.329)$.

Conclusions: Performing easier operations according to ESS in the first years of the learning curve is beneficial in preventing complications. With increasing experience, more complicated procedures can be performed with similar complication rates.

Keywords: Laparoscopy, urology, intraoperative complications, postoperative complications

$\mathrm{Si}^{\mathrm{i}}$ ince the introduction of laparoscopic nephrectomies, laparoscopic surgeries in the field of urology have become increasingly popular and they are now routine procedures in many clinics [1]. Laparo- scopic surgery has its advantages, but carries the risk of complications like all interventions. Using common standardized systems for grading and recording surgical complications allows comparing operations per- 
formed in different centers with different techniques to more meaningful criteria [2]. For this purpose, a grading system in 1992 by Clavien that allows classification of complications and this system was updated in 2004 by the same group [3]. The European Scoring System (ESS) is used to assess the degree of difficulty of laparoscopic surgeries [4].

In the literature, the articles reporting complications of laparoscopic urological procedures and investigating the factors associated with complications were published [5-13]. Many parameters have been associated with perioperative complications, such as the surgeon's experience [12-15]. Performing challenging laparoscopic procedures has increased the experience and therefore the subject should be reevaluated. In our study, we aimed to present our experience with consecutive 942 urological laparoscopic procedures for the upper urinary system.

\section{METHODS}

After getting the approval of the Local Ethics Committee (2014/225); data from 942 laparoscopic surgical procedures for the upper urinary tract between December 2006 and January 2016 were evaluated. These surgeries were performed by a single surgeon (V.T). Outcomes were prospectively collected and retrospectively evaluated.

All patients received preoperative antibiotics and prophylaxis for deep vein thrombosis (compression stockings, subcutaneous low molecular weight heparin). A nasogastric tube and urethral catheter were placed at the beginning of the operation. A veress needle or Hasson technique was used to achieve pneumoperitoneum for the transperitoneal approach. Open access or balloon dilation was performed for the retroperitoneal approach.

The procedures divided into three groups according to the ESS Classification; renal cyst excision was regarded as "easy"; pyeloplasty, simple and radical nephrectomy, nephroureterectomy, ureterolithotomy and pyelolithotomy operations were regarded as "difficult", partial and donor nephrectomy operations were regarded as "very difficult" [4]. The complication rate of each group was calculated separately. Perioperative bleeding was defined as bleeding requiring blood transfusion. Open conversion was excluded from com- plications and analyzed separately. Written informed consent was taken from all patients.

\section{Statistical Analysis}

Chi Square or Fisher exact test were used for categorical variables. Two-tailed $p$ values $<0.05$ was considered as statistically significant. Data are shown as mean \pm SD. Data were analyzed using Statistical Package for Social Sciences (SPSS) 20 software (SPSS Inc., Chicago, IL, United States).

\section{RESULTS}

The mean age of the 942 patients included in the study was $43.7 \pm 14$ years. The study included 576 (61.1\%) male and $366(38.8 \%)$ female patients. The mean BMI was $25.1 \pm 2.3 \mathrm{~kg} / \mathrm{m} 2$, the mean operation time was $125.7 \pm 43.6$ minutes and the mean blood loss was $85.3 \pm 54.9 \mathrm{cc}$. The duration of hospital stay was $3.5 \pm 1.4$ days. Data for all patients are given in Table 1. Procedures included pyeloplasty $(\mathrm{n}=114$, $12.1 \%)$, ureterolithotomy $(\mathrm{n}=223,23.6 \%)$, pyelolithotomy $(n=55,5.8 \%)$, simple nephrectomy

\section{Table 1. Patients characteristics, peroperative and} post operative datas

\begin{tabular}{lc}
\hline Parameters & mean \pm SD or n (\%) \\
\hline Age (years) & $43.7 \pm 4.7$ \\
Male gender & $576(61.1)$ \\
\hline BMI $\left(\mathrm{kg} / \mathrm{m}^{2}\right)$ & $25.1 \pm 2.3$ \\
\hline Side (right/left) & $451(47.88) / 491(52.12)$ \\
Retroperitoneal approach & $380(40.3)$ \\
ASA & $1.5 \pm 0.5$ \\
CCI & $0.7 \pm 0.9$ \\
Operation time (min) & $125.7 \pm 43.6$ \\
EBL (cc) & $85.3 \pm 54.9$ \\
LOS (day) & $3.5 \pm 1.4$ \\
ESS & $41(4,3)$ \\
\multicolumn{1}{c}{ Easy } & $787(83.5)$ \\
\multicolumn{1}{c}{ Diffucult } & $114(12.1)$ \\
\hline \multicolumn{2}{c}{ Very diffucult }
\end{tabular}


Table 2. Number of procedures and complications.

\begin{tabular}{lcccccc}
\hline Procedure & ESS & \multicolumn{5}{c}{ CDCC } \\
\hline & & $\mathrm{n}(\%)$ & Grade 1 & Grade 2 & Grade 3 & Total n (\%) \\
Renal Cyst Resection & 5 & $41(4.3)$ & 0 & 3 & 0 & $3(7.3)$ \\
Ureterolitotomy & 7 & $223(23.6)$ & 7 & 16 & 12 & $35(15.6)$ \\
Pyelolithotomy & 7 & $55(5.8)$ & 2 & 5 & 2 & $7(12.7)$ \\
Simple Nephrectomy & 10 & $150(15.9)$ & 0 & 13 & 1 & $14(9.3)$ \\
Nephroureterectomy & 12 & $25(2.6)$ & 1 & 4 & 0 & $5(20)$ \\
Pyeloplasty & 13 & $114(12.1)$ & 8 & 7 & 2 & $17(14.9)$ \\
Radical Nephrectomy & 13 & $220(23.3)$ & 0 & 22 & 5 & $27(12.2)$ \\
Partial Nephrectomy & 15 & $59(6.2)$ & 5 & 5 & 2 & $12(20.3)$ \\
Donor Nephrectomy & 16 & $55(5.8)$ & 0 & 7 & 0 & $7(12.7)$ \\
\hline
\end{tabular}

ESS $=$ European Scoring System, CDCC $=$ Clavien Dindo Complication Classification

$(\mathrm{n}=150,15.9 \%)$, radical nephrectomy $(\mathrm{n}=220$, $23.3 \%)$, donor nephrectomy $(\mathrm{n}=55,5.8 \%)$, nephroureterectomy $(\mathrm{n}=25,2.6 \%)$, partial nephrectomy $(n=59,6.2 \%)$ and renal cyst excision $(n=41$, $4.3 \%$ ). Retroperitoneal approach was applied to $40.3 \%$ of the cases.

A total of $127(13.4 \%)$ complications were observed. Partial nephrectomy, nephroureterectomy and ureterolithotomy had the highest complication rates, with rates of $20.3 \%, 20 \%$ and $15.6 \%$, respectively. Renal cyst excision, simple nephrectomy and radical nephrectomy had the lowest complication rates, with rates of $7.3 \%, 9.3 \%$ and $12.2 \%$, respectively. The distributions of the cases and the complication rates are shown in Table 2. According to the Clavien Complication Classification, the distributions of Grade 1, 2 and 3 complications were $29.1 \%(n=37), 57.4 \%(n=$ $73)$ and $13.3 \%(n=17)$ respectively. Grade 4 and 5 complications were not observed in any of the cases [3]. Data about complications are listed in Table 3.

The open conversion rate was $0.84 \%(n=8)$; during pyeloplasty $(n=2)$, partial nephrectomy $(n=2)$, pyelolithotomy $(\mathrm{n}=2)$, radical nephrectomy $(\mathrm{n}=1)$ and ureterolithotomy $(\mathrm{n}=1)$. There was no significant difference in the open conversion rates between the transperitoneal and retroperitoneal approaches. Open conversion was performed in two cases during partial nephrectomy due to massive bleeding; in five cases in pyeloplasty, pyelolithotomy and ureterolithotomy, due to technical difficulties, and in one case in radical nephrectomy due to massive perirenal adhesions.
Pyelolithotomy and partial nephrectomy had the highest open conversion rates with $3.6 \%$ and $3.3 \%$, respectively.

The patients were divided into two groups according to the presence of complications. Operation time, estimated blood loss, open conversion rate and length of hospital stay were significantly higher in patients who had complications. In univariate and multivariate analyzes, none of the parameters could predict the presence of complications.

When procedures were classified as "easy", "dif-

\section{Table 3. Complications}

\begin{tabular}{lc}
\hline Complications & n (\%) \\
\hline Fever & $37(3.9)$ \\
Ileus & $34(3.6)$ \\
Ureteral stent requirement & $12(1.2)$ \\
Port side infection & $9(0.9)$ \\
\hline Prolonged drainage & $8(0.8)$ \\
Peritoneal tear & $7(0.7)$ \\
Secondary UPJ stricture & $4(0.4)$ \\
Gonadal vein injury & $4(0.4)$ \\
Liver injury & $4(0.4)$ \\
Subcutaneous emphsema & $3(0.3)$ \\
Colonic injury & $3(0.3)$ \\
Vertebrale artery injury & $1(0.1)$ \\
Renal vein Injury & $1(0.1)$ \\
\hline
\end{tabular}

$\mathrm{UPJ}=$ Uretero-pelvic junction 
ficult" and "very difficult" according to the ESS classification; complication rates were found $7.3 \%$ in the easy group, $13.3 \%$ in the difficult group and $16.6 \%$ in the very difficult group. There was no significant difference between the three groups in terms of complication rates $(p=0.329)$.

\section{DISCUSSION}

Many complications have been published in the urology field since the definition of laparoscopic surgery. Complications of laparoscopic urological procedures rates are variable and were given in the literature from $4.4 \%$ to $23.1 \%$ [6-16]. In their early laparoscopic experience, Parra et al. [5] reported their rate of complications 15\%. Soulie et al. [8] found an overall complication rate of $6.9 \%$ in a large study with 1.085 cases. In parallel with the increasing number of performed more complex urological laparoscopic surgery, published complication rates have increased. Vallancien et al. [9] reported a complication rate as $22 \%$ and an open conversion rate as $1.2 \%$. Sanli et al. [10] reported a $23.1 \%$ rate of overall complications. In our study, we have found a $13.4 \%$ rate of total complications with $10.9 \%$ and $2.5 \%$ of minor and major complication rates, respectively. Our open conversion rate was $0.84 \%$.

Guillonneau et al. [4] have defined a novel scoring system that classifies all laparoscopic procedures according to their difficulty and complexity. The ESS is the most effective scoring system to provide the integrity of a scientific common language and to standardize the results of the studies about laparoscopic urologic procedures. Inoue et al. [11] divided each procedure into three groups according to the ESS. For the easy, difficult, and very difficult groups; the complication rates were $0 \%, 13.2 \%$ and $12.8 \%$, respectively. They demonstrated that the complication rate was significantly low in the easy group and that the nephroureterectomy had the highest rate [11]. In our study, the procedures with the highest complication rates were partial nephrectomy, nephroureterectomy and ureterolithotomy. When the groups were separated as "easy", "difficult" and "very difficult", no significant difference was observed in complication rates.

It has been found that simpler procedures such as renal cyst excision or simple nephrectomy were gen- erally performed in the first years of the learning curve, and more complicated operations like donor nephrectomy or partial nephrectomy were performed with the increasing experience over the years. With this result, we thought that, despite more difficult procedures like partial nephrectomy or nephroureterectomy having higher complication rates, the complication rates were similar between three divided groups due to performing more complicated operations with more increased experience over the years. In the light of this analysis; we think that the complication rates can be kept low by preferring easier operations in terms of ESS score in the first year of learning curves.

Studies have shown that the presence of a high American Society of Anesthesiologists (ASA) score is associated with high complication rates [10-13, 17]. There was no relationship between any parameters with complications or open conversions in our study. We have found that the complication and open conversion rates were similar in transperitoneal and retroperitoneal procedures [18].

The main strengths of our study are the presentation of a large series, including all patients treated by a single surgeon from the beginning of the learning curve. The most important limitation is the retrospective nature.

\section{CONCLUSION}

Performing easier operations according to ESS in the first years of the learning curve is beneficial in preventing complications. With increasing experience, more complex procedures can be performed with similar complication rates, but complication rates are still high in "very difficult" operations such as partial nephrectomy and nephroureterectomy.

\section{Authors'contribution}

Study Conception: ME, VT; Study Design: ME, SŞ, NCŞ; Supervision: KGŞ, VT, SŞ; Funding: İE, SK, VT; Materials: IE, SK, VT; Data Collection and/or Processing: SK, AHY, DNÖ; Statistical Analysis and/or Data Interpretation: ME, SŞ, SK; Literature Review: ME, SŞ, IE, SK, VT; Manuscript Preparation: ME, VT, KGŞ, DNÖ and Critical Review: KGŞ, İE, SK, VT. 


\section{Conflict of interest}

The authors disclosed no conflict of interest during the preparation or publication of this manuscript.

\section{Financing}

The authors disclosed that they did not receive any grant during conduction or writing of this study.

\section{REFERENCES}

1. Clayman RV, Kavoussi LR, Soper NJ, Dierks SM, Meretyk S, Darcy MD, et al. Laparoscopic nephrectomy: initial case report. J Urol 1991;146:278-82.

2. Gonzalgo ML, Pavlovich CP, Trock BJ, Link RE, Sullivan W, Su LM. Classification and trends of perioperative morbidities following laparoscopic radical prostatectomy. J Urol 2005; 174:1359.

3. Dindo D, Demartines N, Clavien PA. Classification of surgical complications: a new proposal with evaluation in a cohort of 6336 patients and results of a survey. Ann Surg 2004;240:20513.

4. Guillonneau B, Abbou CC, Doublet JD, Gaston R, Janetschek G, Mandressi A, et al. Proposal for a "European scoring system for laparoscopic operations in urology." Eur Urol 2001;40:2-7.

5. Parra RO, Hagood PG, Boullier JA, Cummings JM, Mehan DJ, Griffith DP. Complications of laparoscopic urological surgery: Experience at St. Louis University. J Urol 1994;151:6814.

6. Fahlenkamp D, Rassweiler J, Fornara P, Frede T, Loening SA. Complications of laparoscopic procedures in urology: experience with 2,407 procedures at 4 German centers. J Urol 1999;162:76577

7. Cadeddu JA, Wolfe JS Jr, Nakada S, Chen R, Shalhav A, Bishoff JT, et al. Complications of laparoscopic procedures after concentrated training in urological laparoscopy. J Urol 2001;166:2109-11.

8. Soulié M, Salomon L, Seguin P, Mervant C, Mouly P, Hoznek
A, et al. Multi-institutional study of complications in 1085 laparoscopic urologic procedures. Urology 2001;58:899-3.

9. Vallancien G, Cathelineau X, Baumert H, Doublet JD, Guillonneau B. Complications of transperitoneal laparoscopic surgery in urology: review of 1,311 procedures at a single center. J Urol 2002;168:23-6.

10. Permpongkosol S, Link RE, Su LM, Romero FR, Bagga HS, Pavlovich CP, et al. Complications of 2,775 urological laparoscopic procedures: 1993 to 2005. J Urol 2007;177:580-5.

11. Inoue T, Kinoshita H, Satou M, Oguchi N, Kawa G, Muguruma $\mathrm{K}$, et al. Complications of urologic laparoscopic surgery: a single institute experience of 1017 procedures. J Endourol 2010;24:253-60.

12. Colombo JR Jr, Haber GP, Jelovsek JE, Nguyen M, Fergany A, Desai MM, et al. Complications of laparoscopic surgery for urological cancer: a single institution analysis. J Urol 2007;178:786-91.

13. Akin Y, Ates M, Celik O, Ucar M, Yucel S, Erdogru T. Complications of urologic laparoscopic surgery: a center surgeon's experience involving 601 procedures including the learning curve. Kaohsiung J Med Sci 2013;29:275-9.

14. Wolters U, Wolf T, Stützer H, Schröder T. ASA classification and perioperative variables as predictors of postoperative outcome. Br J Anaesth 1996;77:217-22.

15. Charlson ME, Pompei P, Ales KL, MacKenzie CR. A new method of classifying prognostic comorbidity in longitudinal studies: development and validation. J Chronic Dis 1987;40:37383.

16. Sanli O, Tefik T, Erdem S, Ortac M, Salabas E, Karakus S, et al. Prospective evaluation of complications in laparoscopic urology at a mid-volume institution using standardized criteria: experience of 1023 cases including learning curve in 9 years. J Minim Access Surg 2016;12:33-40.

17. Rassweiler JJ, Seemann O, Frede T, Henkel TO, Alken P. Retroperitoneoscopy: experience with 200 cases. J Urol 1998;160:1265-9.

18. Gill IS, Clayman RV, Albala DM, Aso Y, Chiu AW, Das S, et al. Retroperitoneal and pelvic extraperitoneal laparoscopy: an international perspective. Urology 1998;52:566-71. 